\title{
Mining cities are a special type of cities of a traditionally industrial region
}

\author{
Elena Dvoryadkina ${ }^{*}$, and Elvin Jalilov ${ }^{1}$ \\ ${ }^{1}$ Ural State University of Economics, Russia, Yekaterinburg, 620144, 8 Marta str./Narodnoy voli, \\ $62 / 45$
}

\begin{abstract}
The article is devoted to the study of theoretical aspects of mining cities as a special type of cities in a traditionally industrial region. Industry appears both as a factor of cities formation and as the basis for the economic functions of the vast majority of Russian cities. The predominant type of cities are monocities with industry based. It is the combination of cities with a pronounced industrial function, which is steadily implemented over a long period of time, that forms the profile and trajectory of the traditionally industrial region development. The purpose of this article is to identify mining cities as a special type of cities inherent in the traditionally industrial region. The main method of research was the method of typology: the typologies of cities were generalized, industry criteria of typologies were characterized. The result of the study is the justification of mining cities as cities of regional type. The presence of mining cities acts as one of the features (properties) of a traditionally industrial region.
\end{abstract}

\section{Introduction}

Cities are the main element of modern society, because they are almost the most characteristic phenomenon of civilization. Researchers have long ago noticed the relationship between the development of public life and the processes of city evolution. On the one hand, the processes of a new type of economic relations formation, urbanization and urban development, formation of urban culture, urban consciousness, and creation of specific urban infrastructure are mutually dependent, as a result of which cities act as a complex factor of social development and progress. On the other hand, socio-economic and political priorities, directions and needs of social development, tasks set at specific historical stages, led to the emergence of cities and their systems in all their functional diversity.

A unique phenomenon in the urban development of Russia in XVIII - first half XIX century are the factory-cities. They were a new type of settlement, formed on the basis of metallurgical plants. These settlements were entirely dependent on metallurgic plants and were organically interconnected with them. The construction of factory-cities was carried out in accordance with the country's economic needs in metal and the interests of

\footnotetext{
* Corresponding author: dvoryadkina@usue.ru
} 
strengthening its defense capability. Over 150 years (starting from the end of the XVII century), more than 500 metallurgical plants were built in Russia, which corresponds to about an equal number of factory-cities.

Metallurgical plants were built all over Russia - where there were deposits of ores. The main areas of concentration since the end of XVII - beginning of XVIII century became the Centre and the North-East of the country, the Urals; from the second quarter of the XVIII century Siberia joined; from the late XVIII century - the Southern territory; since the beginning of the XIX century - Central Asia; since the mid-XIX century - Caucasus. Each of the metallurgical districts had its own peculiarities of development. Despite the lack of raw materials in the Center and South of Russia in the XVIII century there were built about 100 metallurgical plants. There were more than 30 plants in the Olonets region, the most significant one - Petrovsky - was the beginning of the city of Petrozavodsk. In Siberia, up to 40 factories were operating, by the end of the XIX century they were closed or transferred to private ownership, giving the basis to many settlements, including the city of Barnaul. Most of the plants (over 260) were built in the Urals.

According to one of the major city researchers of the Urals, L.E. Iofa, "... to the feverish construction of iron and copper plants in the Urals" led "a change in the structure of the national economy in the direction of strengthening the role of industry, and in the latter - metallurgy" [1]. The choice of the Urals was due to its "exceptionally great" superiority over other metallurgical regions in terms of the quantity, quality and easy availability of natural resources - ores and forest resources.

The processes associated with city formation based on metallurgical plants have led to the use of such terminology: "factory-city", "mountain city", "mining city". In addition, this type of industrial cities was introduced into the functional typology of urban settlements.

\section{Materials and methods}

Mining cities are a traditional type of industrial cities for the Urals [2]. The main cityforming factor in this case is precisely industry. Because only it was able, firstly, to gather in one place a significant mass of workers; secondly, to feed them on its own; and thirdly, to make the growth of the city almost limitless thanks to the introduction of machines and the desire of industry to concentrate [3].

Industry contributed to the concentration of labor, production, financial, innovative, scientific, technical and technological potential of mankind. This led to a high technical equipment of labor and increased its productivity in all sectors of the economy, provided the formation of the factory system, the creation of large production and industrial centers, as well as urban processes - increasing the role of cities, urban lifestyle and urban culture in the development of society [4].

The importance of industry as a city-forming factor is thoroughly justified in the scientific literature of the 1960s and 1970s.

J. Beaujeu-Garnier and G. Chabot characterize the process of industrial development as leading "to the formation of cities, because developing, it tends to concentrate... But if industry generates cities, then cities in turn contribute to the development of industry" [5].

Historian P.G. Ryndzyunsky named the development of industry as "the most significant factor in urban development", and pointed out that "manufactories with forced labor were often large in size and their location in cities significantly affected the overall appearance of these cities. We should evaluate the presence of such factories as a factor of urban development" [6].

Urban planners Yu.P. Bocharov and O.K. Kudryavtsev substantiated that industry is the main city-forming factor and "it has a decisive influence on the planning structure of modern cities" [7]. 
Economists M.V. Borschevsky, S.V. Uspensky, O.I. Shkaratan concluded that "the urban branches of material production are primarily industries" [8].

Economic geographer B.S. Khorev also paid attention to industry as the main cityforming factor in his researches [9]. Industry not only plays a city-forming role, but also acts as a certain type of activity that justifies the existence and development of the city, provides the necessary resources for life. In other words, the city can be attributed with the implementation of industrial function.

Modern research also substantiates the leading role of industry in the city functioning, which is confirmed by the course of industrialization and neo-industrialization processes. For Example, N.V. Gontar notes: "Russian industry remains the basic sector of the economy (which can also be interpreted as an element of sustainability), setting the vector for the regions and major cities development, although in the latter case, the industrial function is supplemented by service, management, scientific and educational specializations. The modern role of industry, despite the myths about the post-industrial world, is no less important for the countries and regions development, the formation and maintenance of territorial competitiveness, and for the rational organization of Russianscale spaces." [10]

\section{Results and discussion}

Mining cities belong to the industrial type of cities, which is quite widely represented in the cities typologies.

Among the functional typologies, it is necessary to distinguish the typology of cities by Yu.G. Saushkin, which is based on the participation of cities in the territorial division of labor. Thus, urban settlements are combined into the following groups:

1) raw materials and fuel-power cities, which usually include relatively small urban settlements located near exploited mineral deposits, near power plants, towns collecting forest from the surrounding area and performing its primary processing (as well as agricultural and marine raw materials);

2) cities where the main mass production facilities are located with processing, as a rule, of huge masses of raw materials and fuel supplied from many small urban settlements of the previous group;

3) cities that specialize in the production of parts and semi-finished products made of metals, wood, chemical products, etc., obtained from large cities of the previous group;

4) cities where final industrial products are produced, machines and equipment are assembled, and final products of consumer goods industry and other industries are produced; industries;

5) cities with preponderance of people employed in transport and other distribution

6) cities of science and higher education, which include university cities and research centers;

7) cities that specialize in tourism;

8) management cities, which include specially created capital cities, centers of various regions, centers of large industrial companies, etc.;

9) other cities [11].

Describing industrial cities, E.N. Percik noted their great diversity. The most common are cities where various industries are combined, often forming complete production cycles, and sometimes loosely connected to each other. They arise mainly in developed industrial areas with a multi-industry structure, grow very quickly and have a complex territorial structure. Many industrial cities have a narrow industrial specialization, for example, the cities-centers of the metallurgical industry, mechanical engineering, chemical industry, 
forestry and timber processing industry. It is in the group of metallurgical centers that mining towns fall [12].

I.V. Manaeva considers it appropriate to typologize cities according to various criteria, including the type of economy of the city - non-diversified or diversified. "Cities with non-diversified economy are called monocities. Monocity is a locality that legally has the status of a city and operates on the basis of a city-forming enterprise, the financial condition of which determines the quality of life of the population and the social and economic development of the city as a whole. Monocities are ubiquitous in Russia" [13]. One of the types of monocities in the perspective of this typology are industrial cities, which the author identifies as the basis of the economy.

Ushakova V.A. classifies them by the development level of the industrial function of the city, where she highlights: cities with underdeveloped industrial functions; cities with relatively developed industrial functions; cities with developed industrial functions; cities with predominant industrial functions [14].

In the study of Konovalova T.A., the classification of single-industry cities themselves is carried out. The author identifies 8 classification criteria of single-industry city. But we are particularly interested in the branch in which the author distinguishes 4 types of single-industry cities: monocities formed in the region of concentration of natural resources; monocities of power profile; monocities of processing industries; monocities of "high technology" sphere [15].

Starovoitov M.K., Medvedeva L.N. assert that when conducting functional typology, "subtypes are structured in the cities". Industrial cities, according to the author, are divided into: centers of manufacturing industry; centers of extractive industry; centers of consumer goods and heavy industry [16].

Thus, the industrial type of cities is clearly reflected in the industry typologies of cities, since industry is localized in cities and it is the most important city-forming role that belongs to it. In addition, it is the presence of single-industrial cities that is one of the key features of the traditionally industrial region, and mining cities act as such.

\section{Conclusion}

In our opinion, taking into account the typologies analyzed above, mining cities are a regional type of cities typical for regions with the corresponding economic specialization. In this case, such a major economic activity is metallurgical production. The concept of "mining city" is a component, complex concept that includes three main content characteristics:

1) mining city is a city which economic specialization is based on the extraction and processing of metal ores;

2) mining city necessarily has a special architectural and planning structure based on the mandatory presence of rivers as a mechanical force for mining activities;

3) mining cities did not initially have the status of an urban settlement, they had the status of a settlement near factories and were called factories.

Thus, the mining city appears as a special type of industrial cities, which has a certain economic specialization associated primarily with metallurgical production, as an integral territorial and economic entity with a pronounced industrial function. Mining towns on the territory of Russia are located mainly in the Urals, where initially there were mineral deposits and other natural resources necessary for the operation of metallurgical plants. The development of mining towns, as an evolutionary process, has a cyclical-wave character. Each stage of their development is characterized by the features of their functioning, which affect their position in the system of urban settlements in the traditionally industrial region. 


\section{References}

1. L.E. Iofa, Cities of the Urals. Part 1. Feudal period, 93-94 (Moscow, 1951)

2. E.G. Animitsa, E.B. Dvoryadkina, V.G Nekrasov, Mining towns: scientific and theoretical aspects of research (Yekaterinburg, 2004)

3. E.G. Animitsa, N.Yu. Vlasova Urban studies, 50 (Yekaterinburg, 1998)

4. E.B. Dvoryadkina, N.V. Sbrodova, Journal of the Ural State University of Economics, 3 (22), 8-13 (2008)

5. J. Beaujeu-Garnier, G. Chabot, Essays on the geography of the cities, 142 (Moscow, 1967)

6. P.G. Ryndzyunsky, Main factors of urban formation in Russia of the second half of the XVIII century, Russian city (historical and methodological collection), 123 (Moscow, 1976)

7. Yu.P. Bocharov, O.K. Kudryavtsev, Planning structure of a modern city, 7 (Moscow, 1972)

8. M.V. Borschevsky, S.V. Uspensky, O.I. Shkaratan, The city. Methodological problems of integrated social and economic development, 81 (M., 1975)

9. B.S. Khorev, Problems of cities, 179 (M., 1975)

10. N.V. Gontar, Factors and modern features of placement of the industrial complex of Russia, 5 (Moscow: REU n.a. G.V. Plekhanov, 2013)

11. Yu.G. Saushkin Economic geography: history, theory, methods and practice, 374-376 (Moscow, 1973)

12. E.N. Pertsik Geography of the cities (urban geography), 156-157 (M., 1991)

13. I.V. Manaeva, Regional economy: theory and practice, 16 (7), 1239 (2018)

14. V.A. Ushakova, Regional economy: theory and practice, 5, 37-48 (2009)

15. T.A. Konovalova, Regional economy: theory and practice, 36, 41-50 (2012).

16. M.K. Starovoitov, L.N. Medvedeva, Problems of megalopolis development, 6, 71-75 (2008) 